Article

\title{
Physicochemical and Antioxidant Properties of Black Garlic
}

\author{
Il Sook Choi ${ }^{\dagger}$, Han Sam Cha ${ }^{\dagger}$ and Young Soon Lee * \\ Department of Food and Nutrition, Kyung Hee University, 1 Hoeki-dong, Dongdaemun-Ku, \\ Seoul 130-701, Korea; E-Mails: choiis02@khu.ac.kr (I.S.C.); abcing02@gmail.com (H.S.C.) \\ $\dagger$ These authors contributed equally to this work. \\ * Author to whom correspondence should be addressed; E-Mail: yysllee@hanmail.net; \\ Tel.: +82-2-961-0550; Fax: +82-2-961-0260.
}

External Editor: Derek J. McPhee

Received: 11 August 2014; in revised form: 22 September 2014 / Accepted: 29 September 2014 / Published: 20 October 2014

\begin{abstract}
Black garlic (BG) is a processed garlic product prepared by heat treatment of whole garlic bulbs (Allium sativum L.) at high temperature under high humidity for several days, resulting in black cloves with a sweet taste. BG has recently been introduced to the Korean market as a product beneficial to health. To clarify how BG changes during the 35 day aging period, the physicochemical characteristics, antioxidant contents, and antioxidant activities were evaluated under controlled conditions of $70{ }^{\circ} \mathrm{C}$ and $90 \%$ relative humidity. Reducing sugar and total acidity of $\mathrm{BG}$ increased during the aging period, whereas $\mathrm{pH}$ decreased from $\mathrm{pH} 6.33$ to 3.74. Lightness and yellowness values of BG radically decreased during the aging period, whereas redness values increased significantly. Antioxidant components, including the total polyphenol and total flavonoids contents of $\mathrm{BG}$, increased significantly until the 21 st day of aging $(p<0.05)$ and correspondingly, the antioxidant activities of BG, measured by DPPH, ABTS, FRAP, and reducing power assays, were highest on the 21 st day of aging. These results indicate that BG can be considered to not only possess antioxidant properties during the aging period, but also to reach its optimal antioxidant properties at the 21 st day of aging.
\end{abstract}

Keywords: black garlic; aging period; physicochemical characteristics; antioxidant contents; antioxidant activities 


\section{Introduction}

Garlic (Allium sativum L.), belonging to the Alliaceae family, is a frequently used ingredient in gastronomy. Garlic has also been used as a traditional medicine for a variety of biological effects, such as increasing stamina, aiding digestion to prevent diarrhea and worm infestation, and treating heart disease, arthritis, and fatigue [1]. Recently, numerous studies have shown garlic to possess a wide range of bioactive effects, including antioxidant, antimicrobial, anticancer, antihypertensive, hepatoprotective, and insecticidal properties [2]. Although the bioactive properties of garlic are related to antioxidant polyphenolic and bioactive sulfur compounds [3], when garlic is crushed or damaged, some of these bioactive sulfur components produce a strong pungent odor, which are associated with an unpleasant body and breath odor in consumers. The garlic preparation processes are important factors when choosing a garlic supplement because of the various biologically active compounds of garlic present and consumer acceptance. Several garlic products, such as dehydrated garlic powder, garlic essential oil, garlic oil macerate, and aged garlic extract have been introduced to the market and are currently available [4].

Black garlic (BG) has been recently introduced to the Korean market as a health product. BG is formed by aging whole garlic at high temperature and in high humidity, causing the garlic to turn black because of browning compounds. Furthermore, BG does not exude a strong off-flavor, like fresh garlic. This is because of changes to the compound allicin, which is responsible for the pungent odor, into water soluble antioxidant compounds such as $S$-allylcysteine, tetrahydro- $\beta$-carbolines, biologically active alkaloids, and flavonoid-like compounds [3,5]. S-Allylcysteine is formed by the catabolism of $\gamma$-glutamylcysteine and it inhibits oxidative damage related with aging and various diseases [6]. Tetrahydro- $\beta$-carboline derivatives, which have been identified in BG extracts, also show antioxidant effects $[7,8]$. Tetrahydro- $\beta$-carboline derivatives are formed by condensation between tryptophan and aldehyde, similar to the production of pyruvic acid by the allin-allicin pathway or the Maillard reaction process [5]. Furthermore, several studies have reported that BG extracts have antioxidative, anti-allergic, anti-diabetic, anti-inflammatory, hypocholesterolemic, hypolipidemic, and anti-carcinogenic effects [5-14]. However, these studies have used various aging conditions, ranging from 4 to 40 days. Therefore, we hypothesized that there should be optimum aging conditions to maximize the antioxidant properties of BG. Our objective of this study was thus to identify the physicochemical properties of BG during 35 days of aging, and to identify the optimum aging period for maximized antioxidant properties. To achieve this, we quantified the bioactive compound levels, including total polyphenols and flavonoids contents, and antioxidant activities of BG, using 1,1-diphenyl-2-picryl hydrazyl (DPPH), 2,2-azino-bis-(3-ethylbenozothiazoline-6-sulfonic acid) (ABTS), ferric reducing antioxidant power (FRAP), and reducing power assays.

\section{Results and Discussion}

\subsection{Physicochemical Properties of Black Garlic}

The physicochemical characteristics of BG during the aging period are presented in Table 1 . The total acid content of BG increased significantly compared to that of raw garlic, while the $\mathrm{pH}$ of $\mathrm{BG}$ significantly decreased from 5.49 to 3.74 , when compared to 6.33 in raw garlic, during the aging 
period $(p<0.05)$. This result is in agreement with the report of Shin et al. [15], which showed that the $\mathrm{pH}$ of $\mathrm{BG}$ decreased from 6.40 to 5.29 after 6 days of aging. The reducing sugar content of BG increased approximately 6-fold, from $2.73 \mathrm{~g} / \mathrm{kg}$ on the 7 th day to $16.07 \mathrm{~g} / \mathrm{kg}$ on the 35 th day, and these values were significantly higher than those of raw garlic $(1.52 \mathrm{~g} / \mathrm{kg})$. This result is in agreement with the data of Choi et al. [16], which show that sugar content (e.g., glucose, fructose, sucrose, and maltose) increased in BG compared to fresh and steamed garlic. Furthermore, this increased sugar content of BG might be related to its sweet taste.

Color is one of the most important psychological properties of food products that affect the perception of eating in consumers. The color of BG changed to dark brown during the aging period (Figure 1, Table 1). Color redness (a* value) of BG dramatically increased during the aging period, while lightness ( $\mathrm{L}^{*}$ value) and yellowness $\left(\mathrm{b}^{*}\right.$ value) decreased relative to raw garlic. Next, we focused on the impact of BG color development using UV-visible spectroscopy. Figure 2 shows the difference in spectral patterns between raw garlic and BG during 35 days of aging. Raw garlic showed a maximum absorbance at around $230 \mathrm{~nm}$, while $\mathrm{BG}$, on the 7th day, showed a maximum absorbance at $230 \mathrm{~nm}$, around $280-310 \mathrm{~nm}$, and also slightly at $360 \mathrm{~nm}$. However, on the 14th and 35th day, BG showed additional shoulders around $400-425 \mathrm{~nm}$, whereas on the $21 \mathrm{st}$ day and the 28th day, BG showed maximum absorbance in the visible $425-450 \mathrm{~nm}$ range. Color changes resulting from heat treatment are typically due to the Maillard reaction, known as non-enzymatic browning reaction. According to the property of the reactants involved, the Maillard reaction products are usually associated with the absorbance increases at $280 \mathrm{~nm}, 320-360 \mathrm{~nm}$, and $420-450 \mathrm{~nm}$, corresponding to the initial, intermediate, and final stages of Maillard reaction products (MRPS) formation, respectively [17]. The initial stage of the Maillard reaction produces colorless (about $280 \mathrm{~nm}$ ) intermediates arising from sugar-amine condensation and amadori rearrangement. The intermediate stage (320-360 nm) produces colorless or yellow products via several reactions, such as sugar dehydration, sugar fragmentation, and amino acid degradation (Strecker degradation). The final stage $(420-450 \mathrm{~nm})$ is highly colored with aldol condensation, aldehyde-amine condensation, and formation of heterocyclic nitro compounds. Billaud et al. [18] showed that MRPs derived from glucose and cysteine had one absorption shoulder at $285 \mathrm{~nm}$ with a maximum absorbance at 340-360 nm. The formation of MRPs depends on the processing conditions such as temperature and time [19]. Therefore, color changes of black garlic, such as increasing redness and decreasing lightness and yellowness, may be related to the formation of MRPs during the aging period at $70{ }^{\circ} \mathrm{C}$.

Figure 1. Changes in the color of black garlic during the aging period.

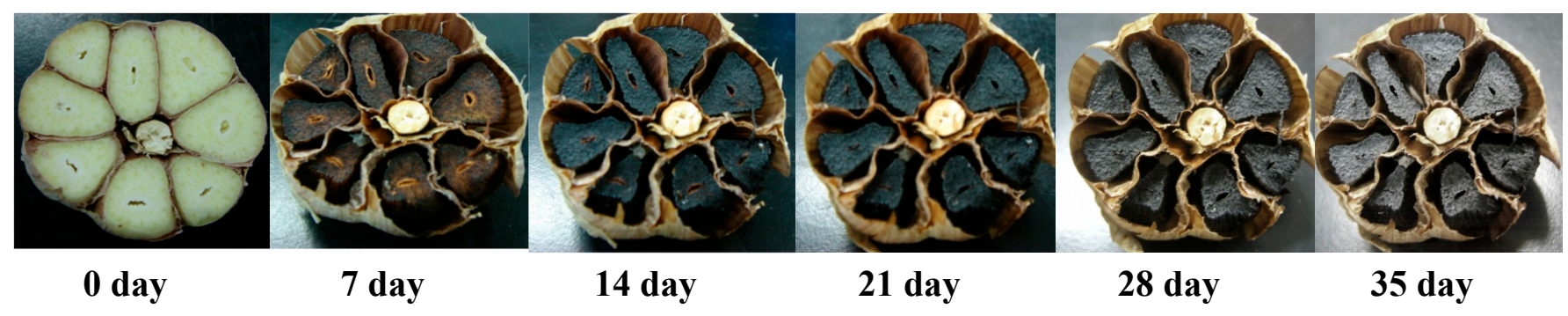


Table 1. Physicochemical characteristics of black garlic during aging period.

\begin{tabular}{ccccccc}
\hline \multirow{2}{*}{ Components } & \multicolumn{5}{c}{ Aging Period (Days) } \\
\cline { 2 - 7 } & $\mathbf{0}$ & $\mathbf{7}$ & $\mathbf{1 4}$ & $\mathbf{2 1}$ & $\mathbf{2 8}$ & $\mathbf{3 5}$ \\
\hline Moisture (\%) & $64.21 \pm 1.48^{\mathrm{a}}$ & $32.72 \pm 0.97^{\mathrm{b}}$ & $31.77 \pm 2.60^{\mathrm{b}}$ & $31.12 \pm 0.17^{\mathrm{b}, \mathrm{c}}$ & $29.55 \pm 0.39^{\mathrm{c}}$ & $29.88 \pm 0.49^{\mathrm{c}}$ \\
Total acidity (mg/kg) & $0.40 \pm 0.01^{\mathrm{e}}$ & $1.30 \pm 0.01^{\mathrm{d}, \mathrm{e}}$ & $1.50 \pm 0.02^{\mathrm{c}, \mathrm{d}}$ & $1.70 \pm 0.03^{\mathrm{c}}$ & $2.30 \pm 0.06^{\mathrm{b}}$ & $2.60 \pm 0.03^{\mathrm{a}}$ \\
pH & $6.33 \pm 0.07^{\mathrm{e}}$ & $5.49 \pm 0.09^{\mathrm{d}, \mathrm{e}}$ & $4.41 \pm 0.17^{\mathrm{c}, \mathrm{d}}$ & $4.22 \pm 0.08^{\mathrm{c}}$ & $4.07 \pm 0.02^{\mathrm{b}}$ & $3.74 \pm 0.062^{\mathrm{a}}$ \\
Reducing sugar (g/kg) & $1.52 \pm 0.01^{\mathrm{d}}$ & $2.73 \pm 0.32^{\mathrm{c}}$ & $12.42 \pm 0.85^{\mathrm{b}}$ & $15.96 \pm 0.29^{\mathrm{a}}$ & $15.98 \pm 0.23^{\mathrm{a}}$ & $16.07 \pm 0.38^{\mathrm{a}}$ \\
Color & & & & & \\
$\mathbf{L}^{*}$ & $68.44 \pm 1.66^{\mathrm{a}}$ & $15.67 \pm 2.41^{\mathrm{b}}$ & $9.28 \pm 1.74^{\mathrm{c}}$ & $5.61 \pm 0.68^{\mathrm{d}}$ & $5.19 \pm 1.11^{\mathrm{d}}$ & $4.33 \pm 2.02^{\mathrm{d}}$ \\
$\mathbf{a}^{*}$ & $-3.84 \pm 0.46^{\mathrm{c}}$ & $6.13 \pm 0.95^{\mathrm{a}}$ & $5.45 \pm 0.94^{\mathrm{a}}$ & $5.23 \pm 1.06^{\mathrm{a}}$ & $3.18 \pm 1.46^{\mathrm{b}}$ & $2.73 \pm 1.01^{\mathrm{b}}$ \\
$\mathbf{b}^{*}$ & $26.59 \pm 1.76^{\mathrm{a}}$ & $10.65 \pm 4.16^{\mathrm{b}}$ & $2.37 \pm 7.47^{\mathrm{c}}$ & $-3.07 \pm 4.60^{\mathrm{d}}$ & $-3.76 \pm 3.59^{\mathrm{d}}$ & $-3.86 \pm 1.49^{\mathrm{d}}$ \\
\hline
\end{tabular}

Values are mean $\pm \mathrm{SD}$; Values followed by different letters in the same row are significantly different by Duncan's multiple range test $(p<0.05)$.

Figure 2. Visible spectra of black garlic during the aging period.

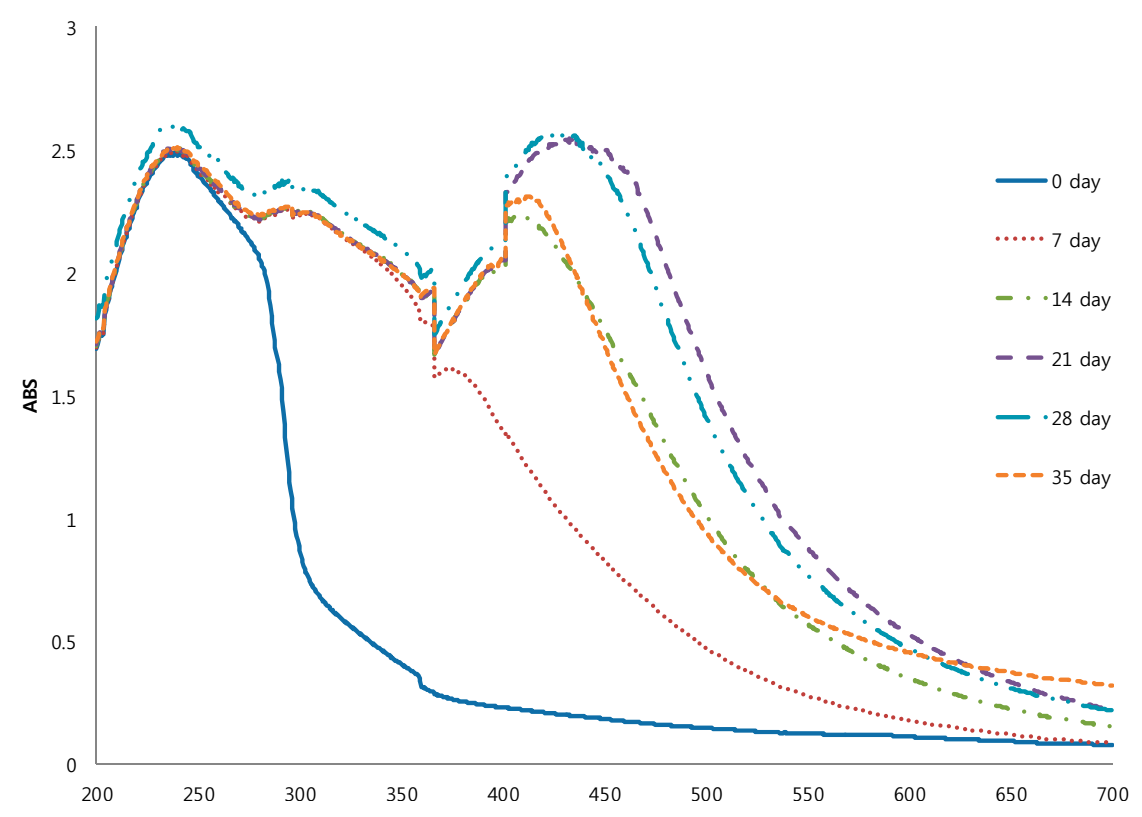

\subsection{Amino Acid Changes of Black Garlic}

Changes in the free amino acids of BG during the aging period are shown in Table 2. Contents of branched amino acids (leucine and isoleucine) were higher in BG than those in raw garlic. Cysteine is an important precursor of sulfur-containing compounds in garlic, such as $S$-methyl-L-cysteine sulphoxide (methiin) and $S$-allyl-L-cysteine sulphoxide (alline), which are the most abundant and the parent cysteine-containing compound responsible for the odoriferous compounds [20]. After processing steps such as cutting, crushing, or dehydration, these compounds are decomposed into other volatile compounds, including diallyl sulfide, diallyl disulfide, diallyl trisulfide, dithirne, and ajocene [3]. Here we found that the sulfur-containing cysteine content of BG decreased significantly during aging and that the cysteine content of BG was lower than that of raw garlic. These results might be associated with the reduced sulfurous flavor of BG. Interestingly, among aromatic amino acids, the phenylalanine content ( 82.38 to $143.07 \mathrm{mg} / 100 \mathrm{~g}$ ) of BG increased during aging and the content was higher than that 
of raw garlic $(55.64 \mathrm{mg} / 100 \mathrm{~g})$, whereas the tyrosine content $(77.31$ to $109.13 \mathrm{mg} / 100 \mathrm{~g})$ of BG decreased dramatically during aging compared to that of raw garlic $(449.95 \mathrm{mg} / 100 \mathrm{~g})$. Hwang et al. [21] reported the MRPs of the sugar-cysteine and sugar-tyrosine model systems were higher in antioxidant activity than those of other MRPs. The decrease of cysteine and tyrosine contents of BG during aging period could be related to the changes of antioxidant activity of BG. Acidic amino acid contents of tyrosine and aspartic acid, and basic amino acid contents of glutamic acid, arginine, and lysine decreased as aging period continued. Likewise, the contents of polar amino acids like threonine and serine, and nonpolar amino acids like glycine and alanine decreased compared to the raw garlic. Therefore, the decrease of these amino acids, especially cysteine and tyrosine, during the aging period might be related to Maillard reactions, which occur between amines which are usually amino acids and carbonyl compounds which are usually reducing sugars.

Table 2. Amino acid contents of black garlic during the aging period.

\begin{tabular}{|c|c|c|c|c|c|c|}
\hline \multirow{2}{*}{$\begin{array}{c}\text { Amino Acid } \\
\text { (mg/100g) }\end{array}$} & \multicolumn{6}{|c|}{ Aging Periods (Days) } \\
\hline & $\mathbf{0}$ & 7 & 14 & 21 & 28 & 35 \\
\hline Leusine & $58.62 \pm 3.37^{\mathrm{b}}$ & $73.44 \pm 1.79^{a}$ & $62.81 \pm 1.51^{\mathrm{b}}$ & $62.12 \pm 5.64^{b}$ & $61.23 \pm 4.32^{b}$ & $59.19 \pm 3.94^{b}$ \\
\hline Isoleucine & $50.04 \pm 13.47^{b}$ & $89.25 \pm 18.93^{\mathrm{a}}$ & $86.45 \pm 8.23^{\mathrm{a}}$ & $83.79 \pm 2.37^{\mathrm{a}}$ & $79.44 \pm 1.14^{\mathrm{a}}$ & $71.07 \pm 2.25^{\mathrm{a}}$ \\
\hline Valline & $47.74 \pm 0.19^{\mathrm{a}}$ & $47.68 \pm 0.64^{\mathrm{a}}$ & $36.71 \pm 4.64^{b}$ & $35.23 \pm 5.61^{b}$ & $34.73 \pm 8.61^{b}$ & $33.91 \pm 6.61^{b}$ \\
\hline Methionine & $31.56 \pm 1.40^{b}$ & $82.51 \pm 4.70^{a}$ & $80.73 \pm 6.37^{\mathrm{a}}$ & $78.11 \pm 2.33^{\mathrm{a}}$ & $73.59 \pm 9.71^{\mathrm{a}}$ & $71.11 \pm 3.55^{\mathrm{a}}$ \\
\hline Cysteine & $81.06 \pm 0.95^{\mathrm{a}}$ & $69.43 \pm 0.94^{b}$ & $49.20 \pm 5.42^{c}$ & $46.90 \pm 8.98^{c}$ & $43.44 \pm 3.38^{\mathrm{c}}$ & $42.14 \pm 7.18^{c}$ \\
\hline Phenylalanine & $55.64 \pm 0.74^{\mathrm{c}}$ & $82.38 \pm 8.35^{b}$ & $70.20 \pm 4.41^{b}$ & $135.16 \pm 7.10^{a}$ & $136.25 \pm 12.76^{\mathrm{a}}$ & $143.07 \pm 6.32^{\mathrm{a}}$ \\
\hline Tyrosine & $449.95 \pm 6.29^{a}$ & $109.13 \pm 26.09^{b}$ & $102.33 \pm 0.38^{b}$ & $82.28 \pm 7.41^{b}$ & $78.35 \pm 4.34^{b}$ & $77.31 \pm 7.54^{b}$ \\
\hline Aspartic acid & $90.12 \pm 2.55^{b}$ & $117.50 \pm 9.07^{\mathrm{a}}$ & $64.53 \pm 5.84^{c}$ & $62.43 \pm 4.34^{\mathrm{c}}$ & $61.65 \pm 9.12^{c}$ & $60.19 \pm 8.16^{c}$ \\
\hline Glutamic acid & $286.60 \pm 8.09^{a}$ & $128.87 \pm 9.09^{b}$ & $112.81 \pm 3.02^{b}$ & $108.11 \pm 9.12^{b}$ & $101.88 \pm 7.71^{b}$ & $100.11 \pm 6.09^{b}$ \\
\hline Arginine & $409.05 \pm 3.00^{\mathrm{a}}$ & $340.20 \pm 75.68^{b}$ & $119.30 \pm 0.52^{d}$ & $208.71 \pm 51.36^{\mathrm{c}}$ & $71.92 \pm 0.65^{\mathrm{d}, \mathrm{e}}$ & $40.34 \pm 1.10^{\mathrm{e}}$ \\
\hline Lysine & $61.68 \pm 5.29^{\mathrm{a}}$ & $57.96 \pm 4.93^{\mathrm{a}}$ & $47.39 \pm 2.24^{b}$ & $42.50 \pm 2.27^{b}$ & $41.53 \pm 3.67^{b}$ & $40.50 \pm 9.22^{b}$ \\
\hline Histidine & $89.12 \pm 1.88^{b}$ & $191.69 \pm 18.89^{\mathrm{a}}$ & $58.76 \pm 13.02^{c}$ & $58.75 \pm 3.59^{c}$ & $57.62 \pm 5.51^{\mathrm{c}}$ & $57.89 \pm 8.34^{c}$ \\
\hline Threonine & $81.25 \pm 13.59^{a}$ & $46.30 \pm 0.87^{\mathrm{b}}$ & $53.53 \pm 8.36^{\mathrm{b}}$ & $57.54 \pm 2.22^{b}$ & $58.36 \pm 11.17^{b}$ & $59.36 \pm 5.22^{b}$ \\
\hline Serine & $38.53 \pm 0.82^{\mathrm{a}}$ & $25.72 \pm 0.87^{b}$ & $25.84 \pm 0.33^{b}$ & $24.78 \pm 1.12^{b}$ & $24.23 \pm 4.22^{b}$ & $23.71 \pm 5.41^{b}$ \\
\hline Glycine & $21.50 \pm 2.51^{b}$ & $37.41 \pm 8.54^{\mathrm{a}}$ & $9.60 \pm 1.78^{c}$ & $8.63 \pm 1.18^{c}$ & ND & ND \\
\hline Alanine & $89.72 \pm 11.44^{b}$ & $239.13 \pm 17.84^{\mathrm{a}}$ & $67.01 \pm 2.39^{\mathrm{c}}$ & $83.59 \pm 5.71^{b}$ & $47.38 \pm 1.74^{\mathrm{d}}$ & $32.74 \pm 5.37^{\mathrm{d}}$ \\
\hline
\end{tabular}

Values are mean $\pm \mathrm{SD}$; Values followed by different letters in the same row are significantly different by Duncan's multiple range test $(p<0.05)$. ND, cannot be detected.

\subsection{Antioxidant Content of Black Garlic}

To clarify the antioxidant properties of BG during aging, we focused on the analysis of total polyphenol and total flavonoids contents (Table 3). The total polyphenol contents (25.81-58.33 mg GAE/g) of BG were not only significantly higher than those of raw garlic (13.91 mg GAE/g) but also increased significantly until the 21th day of aging, before decreasing during the rest of the aging period $(p<0.05)$. According to Kim et al. [22], hydroxycinnamic acid derivatives and other phenolic acid contents are increased over 5-fold in black garlic compared to raw garlic. These increases of phenolic acids might also be related to an increase of the total acid contents of BG. According to $\mathrm{Xu}$ et al. [23], heat treatment of the phenolic compounds increased the free fraction of phenolic acids, whereas it 
decreased the ester, glycoside, and ester-bound fractions, leading to an increase in free phenol forms. Gorinstein et al. [24] showed that the garlic processing conditions lead to changes in the contents of its bioactive compounds, such as polyphenols, flavonoids, and anthocyanins, and that this is connected to the type and duration of treatment. Flavonoids do not only belong to a group of variable phenolic structures but are also found in fruit, vegetables, grains, roots, flowers, tea, and wines [25]. Heat treatment has a large influence on flavonoid availability, dependent on the magnitude and duration of treatment, their sensitivity to heat, and the physicochemical food environment [26]. During heat treatment, total flavonoids content increases and decreases in food products depending on the processing conditions [26]. The total flavonoid content of BG (5.38 mg RE/g to $16.26 \mathrm{mg} \mathrm{RE} / \mathrm{g}$ ) was not only significantly higher than that of raw garlic $(3.22 \mathrm{mg} \mathrm{RE} / \mathrm{g})$, but also increased significantly up to the 21st day of aging, after which the continued to increase slightly for the remainder of the aging period $(p<0.05)$. From the results of total polyphenols, and total flavonoids, the optimum aging period of BG to maximize antioxidant content may be the 21 st day of aging.

Table 3. Antioxidant contents of black garlic during aging period.

\begin{tabular}{ccccccc}
\hline & \multicolumn{5}{c}{ Aging Period (Days) } \\
\cline { 2 - 7 } & $\mathbf{0}$ & $\mathbf{7}$ & $\mathbf{1 4}$ & $\mathbf{2 1}$ & $\mathbf{2 8}$ & $\mathbf{3 5}$ \\
\hline $\begin{array}{c}\text { Total polyphenol } \\
(\mathrm{mg} \text { GAE/g) }\end{array}$ & $13.91 \pm 1.62^{\mathrm{f}}$ & $25.81 \pm 1.59^{\mathrm{e}}$ & $35.28 \pm 0.32^{\mathrm{d}}$ & $58.33 \pm 1.90^{\mathrm{a}}$ & $55.25 \pm 0.70^{\mathrm{b}}$ & $48.35 \pm 1.14^{\mathrm{c}}$ \\
\hline $\begin{array}{c}\text { Total flavonoid } \\
(\mathrm{mg} \mathrm{RE} / \mathrm{g})\end{array}$ & $3.22 \pm 0.07^{\mathrm{d}}$ & $5.38 \pm 0.06^{\mathrm{c}}$ & $8.34 \pm 0.61^{\mathrm{b}}$ & $15.37 \pm 0.52^{\mathrm{a}}$ & $16.26 \pm 1.69^{\mathrm{a}}$ & $15.70 \pm 2.11^{\mathrm{a}}$ \\
\hline
\end{tabular}

$\mathrm{GAE}=$ gallic acid equivalents; $\mathrm{RE}=$ rutin equivalents; Values are mean $\pm \mathrm{SD}$; Values followed by different letters in the same row are significantly different by Duncan's multiple range test $(p<0.05)$.

\subsection{Antioxidant Activity of Black Garlic}

To accurately assess the antioxidant activities of BG, four distinct antioxidant activity measurements were performed. DPPH radical scavenging activity and ABTS assays are characterized by the ability of the corresponding substrates to undergo single electron transfer by two components in the reaction mixture of antioxidants with oxidant, such as the DPPH and ABTS radicals, respectively. The assays are also operationally simple and easy to use [27]. The DPPH free radical scavenging activity of BG (37.32\%-74.48\%) was significantly higher than that of raw garlic (4.65\%) (Figure $3 \mathrm{~A})$. The DPPH free radical scavenging activity of BG increased approximately 2 -fold, from $37.32 \%$ on the 7 th day to $74.48 \%$ on the 21 st day, and then slightly decreased to $63.09 \%$ till the 35 th day of aging. The values were significantly higher than that of raw garlic $(4.65 \%)(p<0.05)$. This pattern of DPPH free radical activity of BG was similar to that of the total polyphenol content (Table 3 ). The ABTS•+ free radical scavenging activity of BG was significantly higher on the 21 st day $(249.20 \mathrm{mM} \mathrm{TE})$, compared to the raw garlic $(92.43 \mathrm{mM} \mathrm{TE})$. The values steadily decreased from the $21 \mathrm{st}$ day to the 35th day (245.45 mM TE) (Figure 3B). These results were similar to the DPPH free radical scavenging effects. Generally, the FRAP assay and reducing power are based on the ability of an electron transfer reaction, with a ferric salt as oxidant. The FRAP assay requires acidic conditions ( $\mathrm{pH} 3.8)$, whereas the reducing power assay occurs at neutral $\mathrm{pH}$ [27]. As shown in Figure 3C, the FRAP values of BG were dramatically higher than those of raw garlic. Like in the other assays, the FRAP value of BG increased 
up to the 21st day of aging and then subsequently decreased. During the aging period, the antioxidant contents (e.g., total polyphenol, total flavonoids) of BG gradually increased up to the 21 st day (Table 3), which is likely associated with the antioxidant results observed in the FRAP assay. Furthermore, the reducing power of $\mathrm{BG}$ also dramatically increased up to the $21 \mathrm{st}$ day $(322.70 \mathrm{mM} \mathrm{TE})$ when compared to raw garlic (30.55 mM TE) (Figure 3D). These results were similar to those obtained in the DPPH, ABTS, and FRAP assays and the increase in the antioxidant activities of BG may be due to the increase in total polyphenols, total flavonoids, and ascorbic acid contents during aging period. Based on the above results of antioxidant compounds and antioxidant activities findings, we propose that the optimum aging period for maximizing the antioxidant properties of BG is 21 days.

Figure 3. Antioxidant activities of black garlic during the aging period. (A) DPPH radical scavenging; (B) ABTS radical scavenging; (C) $\mathrm{Fe}$ (III) reducing (pH 3.6); (D) Fe(III) reducing $(\mathrm{pH}$ 6.6). Different letters above the bars for the same aging periods indicate significant difference at $p<0.05$ (Duncan's test).

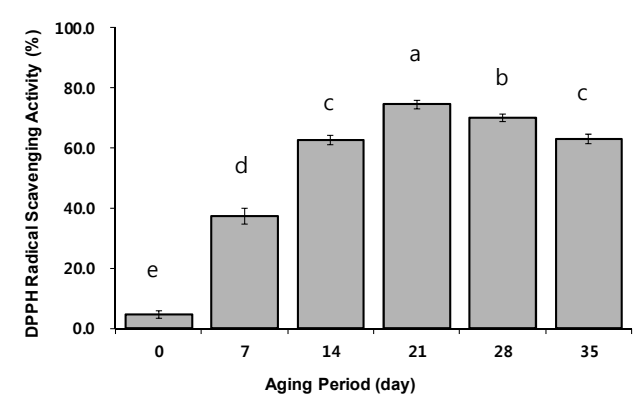

(A)

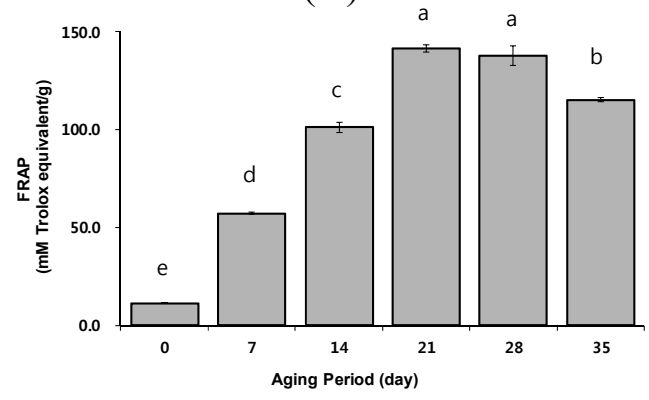

(C)

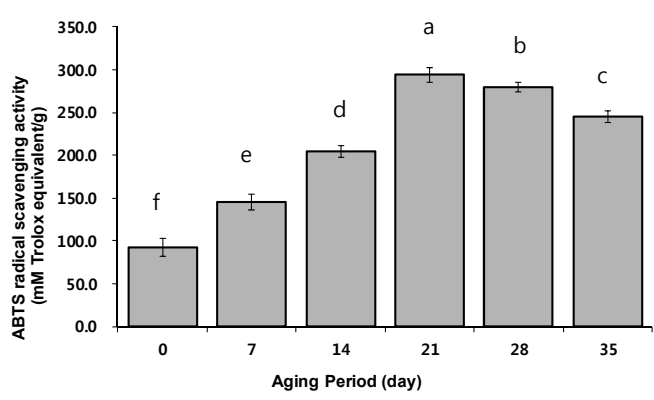

(B)

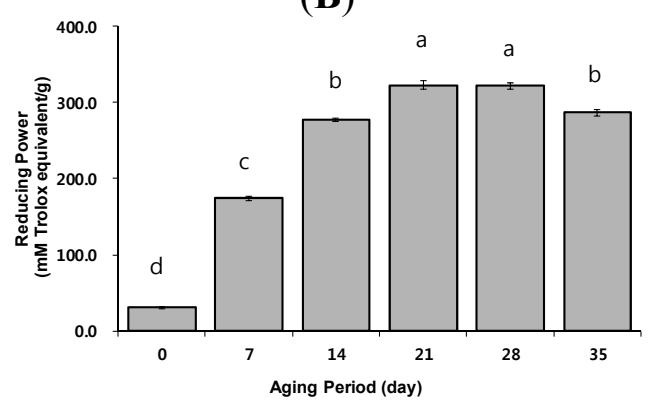

(D)

\section{Experimental Section}

\subsection{Materials and Reagents}

Fresh garlic (Allium sativum L.) was purchased from a local market in the Uiseong Agricultural Association, Gyeongsangbuk-do, South Korea in 2011. Folin-Ciocalteu's reagent, garlic acid, rutin, 1,1-diphenyl-2-picrylhydrazyl (DPPH), 2,2'-azino-bis-(3-ethylbenozothiazoline-6-sulfonic acid) (ABTS), potassium persulphate, trichloroacetic acid (TCA), and potassium ferricynide were purchased from Sigma-Aldrich Chemical Co. (St. Louis, MO, USA). All chemicals and reagents used in this study were of analytical grade. 


\subsection{Preparation and Extraction of Black Garlic Extract}

BG samples were prepared based on the method described in [8]. Ten unpeeled raw garlic heads were incubated in a thermohygrostatic chamber (THPE 025, Jeio Tech, Seoul, Korea) at $70{ }^{\circ} \mathrm{C}$ in $90 \%$ relative humidity for $7,14,21,28$, and 35 days. During the aging process, raw garlic developed a black color. The fresh raw garlic and aged BG cloves were peeled from the bulb and ground by a high-speed mixer (Blaender 7012S, Waring, Torrington, CT, USA). The ground BG was mixed with deionized water at a solid:liquid ratio of 1:3. The samples were extracted three times with deionized water for $1 \mathrm{~h}$ at room temperature in a shaker (CR300, FinePCR, Seoul, Korea). The extracts were centrifuged (4000 rpm, $10 \mathrm{~min}$ ) and supernatants were collected. Collected supernatants were kept at $-70{ }^{\circ} \mathrm{C}$ for 2 days and then dried in a freeze-dryer (Labconco freeze-dry/shell freeze system, Labconco Corp., Kansas City, MO, USA). Finally the dried extracts were stored at $-20{ }^{\circ} \mathrm{C}$ before analysis.

\subsection{Determination of Physicochemical Property}

The moisture content of $\mathrm{BG}$ was determined in accordance with the techniques described by the official AOAC method [28]. The pH of BG was measured by a calibrated $\mathrm{pH}$ meter (Corning 530, Corning Inc., Corning, NY, USA). The total acid content of BG was analyzed by titration of the sample with $0.1 \mathrm{~N} \mathrm{NaOH}$ to $\mathrm{pH} 8.3$ and expressed as a percentage of tartaric acid [28]. Reducing sugar content was analyzed by the DNS method [29].

\subsection{Color Measurements}

Color values of BG were performed using a spectrocolorimeter (JS-555 Color Techno System Co. Ltd., Tokyo, Japan) tristimulus color analyzer calibrated with a white porcelain reference plate. The color coordinates of the uniform color space CIE-LAB L*, $a^{*}, b^{*}$ were determined by its reflectance and chromaticity. The $\mathrm{L}^{*}$ value indicates brightness ranging from black $\left(\mathrm{L}^{*}=0\right)$ to white $\left(\mathrm{L}^{*}=100\right)$. The $\mathrm{a}^{*}$ value indicates redness ranging from -60 (green) to 60 (red) and the $\mathrm{b}^{*}$ value ranges from -60 (blue) to 60 (yellow). Furthermore, in order to confirm the browning development of BG, UV-visible spectra of BG were measured by the absorbance at the range of 200-700 nm using a spectrophotometer (model 1800, Shimadzu, Kyoto, Japan).

\subsection{Determination of Amino Acids}

The amino acids of BG were determined using HP 1100 liquid chromatograph (Hewlett Packard Wilmington, DE, USA) with a variable wavelength detector (VWD HP 1100) operating at $338 \mathrm{~nm}$ (excitation $=340 \mathrm{~nm}$ ). Separation was carried out with a Zorbax Eclipse AAA Rapid Resolution column $(150 \times 4.6 \mathrm{~mm}$ i.d., $5 \mu \mathrm{m}$ particle size, Agilent Technologies, Palo Alto, CA, USA). A linear gradient profile of mobile phase, comprising $40 \mathrm{mM} \mathrm{Na} \mathrm{HPO}_{4}, \mathrm{pH} 7.8$ (solvent A) and $\mathrm{CAN} / \mathrm{MeOH} /$ water 45:45:10 (v/v/v) (solvent B), 0\% B (0-1.9 min), 0\%-57\% (1.9-18.1 min), 57\%-100\% (18.1-18.8 $\mathrm{min}), 100 \%(18.8-22.3 \mathrm{~min}), 100 \%-0 \%(22.3-23.2 \mathrm{~min})$ and $0 \%(23.2-26 \mathrm{~min})$ was applied at a flow rate of $2.0 \mathrm{~mL} / \mathrm{min}$. The column was equilibrated for $5 \mathrm{~min}$ under initial conditions prior to injection of the next samples. The column temperature was $40{ }^{\circ} \mathrm{C}$. In order to determine the amino acids content of BG, precolumn derivatization with $o$-phthalaldehyde (OPA) was used and $0.5 \mu \mathrm{L}$ 
portions were injected into the HPLC system. The data analysis was performed using Chemstation software (Hewlett Packard).

\subsection{Determination of Antioxidant Contents}

The total polyphenol content of BG was determined according to the method described by Arnous et al. [30]. Briefly, an aliquot of diluted BG (2.4 mL) was mixed with Folin-Ciocalteu reagent $(0.15 \mathrm{~mL})$, followed by the addition of $1 \mathrm{M} \mathrm{NaCO}_{3}$ solution $(0.45 \mathrm{~mL})$. The reaction was then allowed to proceed for $1 \mathrm{~min}$. The absorbance at $750 \mathrm{~nm}$ was measured after $30 \mathrm{~min}$ at room temperature in the dark. Total polyphenols content was expressed as milligrams of gallic acid equivalents (GAE).

The total flavonoids content was analyzed according to the method described by Shen et al. [31]. Deionized water $(2 \mathrm{~mL})$ and $0.5 \mathrm{M} \mathrm{NaNO}_{2}(0.15 \mathrm{~mL})$ solution were mixed with $\mathrm{BG}(0.5 \mathrm{~mL})$, and allowed to react at room temperature for $5 \mathrm{~min}$. Then, $0.4 \mathrm{M} \mathrm{AlCl} \cdot 6 \mathrm{H}_{2} \mathrm{O}$ solution $(0.15 \mathrm{~mL})$ was added and the samples were incubated for $5 \mathrm{~min}$ before the addition of $1 \mathrm{M} \mathrm{NaOH}$ solution $(1 \mathrm{~mL})$. The absorbance was measured at $415 \mathrm{~nm}$ after $15 \mathrm{~min}$ incubation. The total flavonoid content was expressed as rutin equivalents (RE).

\subsection{Determination of Antioxidant Activity}

The free radical scavenging activity of BG, based on the scavenging activity of the stable DPPH (2,2-diphenyl-1-picrylhydrazyl) free radical, was determined using the method described by Brand-Willian et al. [32] with slight modifications. A sample of BG $(0.2 \mathrm{~mL})$ was added to $0.2 \mathrm{mM}$ DPPH dissolved in ethanol solution $(0.5 \mathrm{~mL})$. After incubating the solution at room temperature in the dark for $30 \mathrm{~min}$, the absorbance was measured at $517 \mathrm{~nm}$, and the radical scavenging activity was expressed as percent inhibition:

$$
\text { DPPH inhibition }(\%)=([\mathrm{AC}-\mathrm{AS}] / \mathrm{AC}) \times 100
$$

where AC was the absorbance of the control (blank), and AS was the absorbance of the extract.

The free radical scavenging activity of BG, based on the scavenging activity of the stable ABTS•+ [2,2-azinobis-(3-ethylbenzo-thiazoline-6-sulphnate] free radical, was also determined using the method described by Re et al. [33] with slight modifications. A mixture of an oxidant ( $2.45 \mathrm{mM}$ of potassium persulfate) and $7 \mathrm{mM}$ ABTS solution dissolved in $20 \mathrm{mM}$ sodium acetate buffer (pH 4.5) was incubated at room temperature in the dark for 12 to $16 \mathrm{~h}$ to create a stable and dark blue-green radical solution. The solution was then diluted with a PBS (phosphate buffered saline) solution to an absorbance of $0.70 \pm 0.02$ at $734 \mathrm{~nm}$ to create the test reagent as a working solution. Then, $0.03 \mathrm{~mL}$ of diluted BG was added to $3 \mathrm{~mL}$ of the working solution. After incubating the solution at room temperature in the dark for $30 \mathrm{~min}$, the absorbance was measured at $734 \mathrm{~nm}$ and the radical scavenging activity was expressed as mmol/L Trolox equivalent per gram of BG.

The antioxidant capacity of BG was determined using the ferric reducing antioxidant power (FRAP) assay described by Benzie and Strain [34] with some modifications. The stock solutions included $300 \mathrm{mmol} / \mathrm{L}$ acetate buffer (pH 3.6), $10 \mathrm{mM}$ TPTZ (2,4,6-tripyridyl-s-triazine) solution dissolved in $40 \mathrm{mM} \mathrm{HCl}$, and $20 \mathrm{mM} \mathrm{FeCl} \cdot 6 \mathrm{H}_{2} \mathrm{O}$ solution. The working solution was prepared by mixing acetate buffer $(25 \mathrm{~mL})$, TPTZ solution $(2.5 \mathrm{~mL})$, and $20 \mathrm{mM} \mathrm{FeCl} \cdot 6 \mathrm{H}_{2} \mathrm{O}$ solution $(2.5 \mathrm{~mL})$. Black 
garlic $(0.05 \mathrm{~mL})$ was added to the FRAP solution $(0.75 \mathrm{~mL})$ and incubated at room temperature in the dark for $30 \mathrm{~min}$. Color changes were then measured at $593 \mathrm{~nm}$ and the standard curve was linear between 0 to $200 \mu \mathrm{M}$ of Trolox. Result was expressed as mmol/L Trolox equivalent per gram of BG.

The reducing power of $\mathrm{BG}$ was measured according to the method described by Oyaizu [35] with slight modifications. Briefly, BG $(0.1 \mathrm{~mL})$ was mixed with $200 \mathrm{mM}$ sodium phosphate buffer (pH 6.6, $0.25 \mathrm{~mL})$ and $1 \%$ potassium ferrocyanide $(0.25 \mathrm{~mL})$. The mixture was incubated in a water bath $\left(50{ }^{\circ} \mathrm{C}\right)$ for $20 \mathrm{~min}$ and then added to $0.62 \mathrm{M}$ trichloroacetic acid (TCA, $0.2 \mathrm{~mL}$ ) solution to terminate the reaction. The mixture was then mixed with deionized water $(0.2 \mathrm{~mL})$ and $6.17 \mathrm{mM}$ ferric chloride solution $(0.5 \mathrm{~mL})$. The absorbance of the resulting solution was measured at $700 \mathrm{~nm}$ using deionized water as a blank. The reducing potential of the sample was determined against a standard curve of Trolox $(0-200 \mu \mathrm{M})$. Results were expressed as mmol/L Trolox equivalent per gram of BG.

\subsection{Statistical Analysis}

All experiments were carried out in triplicate and data was expressed as mean \pm standard deviation (SD) using SPSS 17.0 version (SPSS Institute, Chicago, IL, USA). One-way analysis of variance (ANOVA) and Duncan's Multiple Comparison Test were used to determine the significance of the difference among samples with a significance level of 0.05 .

\section{Conclusions}

Black garlic (BG), produced by aging whole bulbs of garlic (Allium sativum L.) at $70{ }^{\circ} \mathrm{C}$ in $90 \%$ relative humidity for 35 days, have shown higher antioxidant properties when compared to raw garlic. Moisture content, reducing sugar and total acidity of BG increased significantly until the 21 st day of aging. While lightness and yellowness values of BG decreased dramatically until the 21st day of aging. The maximum absorbance of BG on the $21 \mathrm{st}$ and 28 th days were in the visible ranges of around $450 \mathrm{~nm}$, related to the final stage of the Maillard browning reaction. Total polyphenol and total flavonoids contents of BG significantly increased till the 21 th day of aging, and changed only slightly thereafter. The antioxidant activities of $\mathrm{BG}$ throughout the aging period were consistent with the antioxidant components measured using DPPH, ABTS, FRAP, and reducing power. Therefore, this study of BG might be useful for understanding not only the antioxidant properties of BG, but also its optimum aging conditions for maximized antioxidant properties.

\section{Acknowledgments}

This study was supported by the Kyung Hee University research grants (20100630) in 2010.

\section{Author Contributions}

All the authors contributed to the study through the study design, performed experiments, analyzed data or writing the paper. I.S.C. and Y.S.L. designed the research; H.S.C. and I.S.C. performed the experimental work; H.S.C. and I.S.C. wrote the manuscript. All authors discussed, edited and approved the final version. 


\section{Conflicts of Interest}

The authors declare no conflict of interest.

\section{References}

1. Banerjee, S.K.; Maulik, S.K. Effect of garlic on cardiovascular disorders: A review. Nutr. J. 2002, $1,1-14$.

2. Rahman, K.; Lowe, G.M. Garlic and cardiovascular disease: A critical review. J. Nutr. 2006, 136, 736S-740S.

3. Corzo-Martínez, M.; Corzo, N.; Villamiel, M. Biological properties of onions and garlic. Trends Food Sci. Technol. 2007, 18, 609-625.

4. Amagase, H.; Petsch, B.L.; Matsuura, H.; Kasuga, K.; Itakura, Y. Intake of garlic and its bioactive components. J. Nutr. 2001, 131, 955S-962S.

5. Ichikawa, M.; Ryu, K.; Yoshida, J.; Ide, N.; Yoshida, S.; Sasaoka, T.; Sumi, S.I. Antioxidant effects of tetrahydro- $\beta$-carboline derivatives identified in aged garlic extract. BioFactors 2002, 16, 57-72.

6. Colin-Gonzalez, A.L.; Santana, R.A.; Silva-Islas, C.A.; Chanez-Cardenas, M.E.; Santamaria, A.; Maldonad, P.D. The antioxidant mechanisms underlying the aged garlic extract- and $S$-allylcystein-induced protection. Oxidative Med. Cell. Longev. 2012, 2012, 1-16.

7. Ichikawa, M.; Yoshida, J.; Ide, N.; Sasaoka, T.; Yamaguchi, H.; Ono, K. Tetrahydro- $\beta$-carboline derivatives in aged garlic extract show antioxidant properties. J. Nutr. 2006, 136, 726S-731S.

8. Sato, E.; Kohno, M.; Niwano, Y. Increased level of tetrahydro- $\beta$-carbokine derivatives in short-term fermented garlic. Plant Food Hum. Nutr. 2006, 61, 175-178.

9. Kim, J.H.; Nam, S.H.; Rico, C.W.; Kang, M.Y. A comparative study on the antioxidative and anti-allergic activities of fresh and aged black garlic extracts. Int. J. Food Sci. Technol. 2012, 47, $1176-1182$.

10. Lee, Y.M.; Gweon, O.C.; Seo, Y.J.; Im, J.; Kang, M.J.; Kim, M.J.; Kim, J.I. Antioxidant effect of garlic and aged black garlic in animal model of type 2 diabetes mellitus. Nutr. Res. Pract. 2009, 3, $156-161$.

11. Kim, M.H.; Kim, M.J.; Lee, J.H.; Han, L.J.; Kim, J.H.; Sok, D.E.; Kim, M.R. Hepatoproective effect of aged black garlic on chronic alcohol-induced liver injury in rats. J. Med. Food. 2011, 14, 732-738.

12. Lee, E.N.; Cho, Y.W.; Kim, H.K.; Park, J.K.; Kim, H.J.; Kim, M.J.; Lee, H.W.; Kim, K.H.; Bae, S.S.; Kim, B.S.; et al. Chloroform extract of aged black garlic attenuates TNF- $\alpha$-induced ROS generation, VCAM-1 expression, NF- $\mathrm{BB}$ activation and adhesiveness for monocytes in human umbilical vein endothelial cells. Phytother. Res. 2011, 25, 92-100.

13. Kim, H.K.; Choi, Y.W.; Lee, E.N.; Park, J.K.; Kim, S.G.; Park, D.J.; Kim, B.S.; Lim, Y.T.; Yoon, S. 5-Hydroxymethylfurfural from black garlic extract prevents TNF $\alpha$-stimulated monocytic celll adhesion to HUVECs by suppression of vascular cell adhesion molecule-1 expression, reactive oxygen species generation and NF- $\mathrm{BB}$ activation. Phytother. Res. 2011, 25, 965-974.

14. Kim, I.; Kim, J.Y.; Hwang, Y.J.; Hwang, K.A.; Om, A.S.; Kim, J.H.; Cho, K.J. The beneficial effects of aged black garlic extract on obesity and hyperlipidemia in rats fed a high-fat diet. J. Med. Plants Res. 2011, 5, 3159-3168. 
15. Shin, J.H.; Choi, D.J.; Chung, M.J.; Kang, M.J.; Sung, N.J. Changes of physicochemical components and antioxidant of aged garlic at different temperatures. J. Korean Soc. Food Sci. Nutr. 2008, 37, 1174-1181.

16. Choi, D.J.; Lee, S.J.; Kang, M.J.; Cho, H.S.; Sung, N.J.; Shin, J.H. Physicochemical Characteristics of Black Garlic (Allium sativum L.). J. Korean Soc. Food Sci. Nutr. 2008, 37, 465-471.

17. Nursten, H. The Maillard Reaction: Chemistry Biochemistry and Implications; The Royal Society of Chemistry: Cambridge, UK, 2005; pp. 2-4.

18. Billaud, C.; Maraschin, C.; Nicolas, J. Inhibition of polyphenoloxidase from apple by Maillard reaction products prepared from glucose or fructose with L-cysteine under various conditions of pH and temperature. LWT-Food Sci. Technol. 2004, 37, 69-78.

19. Hardy, J.; Parmentier, M.; Fanni, J. Functionality of nutrients and thermal treatment of food. Proc. Nutr. Soc. 1999, 58, 579-585.

20. Amagase, H. Clarifying the bioactive constituents of garlic. J. Nutr. 2006, 136, 716S-725S.

21. Hwang, I.G.; Kim, H.Y.; Woo, K.S.; Lee, J.; Jeong, H.S. Biological activites of Maillard reaction products (MRPs) in a sugar-amino acid model system. Food Chem. 2011, 126, 221-227.

22. Kim, J.S.; Kang, K.J.; Gweon, O.C. Comparison of phenolic acids and flavonoids in black garlic at different thermal processing steps. J. Funct. Foods 2013, 5, 80-86.

23. Xu, G.; Ye, X.; Chen, J.; Liu, D. Effect of heat treatment on the phenolic compounds and antioxidant capacity of citrus peel extract. J. Agric. Food Chem. 2007, 55, 330-335.

24. Gorinstein, S.; Leontowicz, H.; Leontowicz, M.; Namiesnik, J.; Najman, K.; Drzewiecki, J.; Cvikrova, M.; Martincova, O.; Katrich, E.; Trakhtenberg, S. Comparison of the main bioactive componunds and antioxidant activities in garlic and white and red onions after treatment protocols. J. Agric. Food Chem. 2008, 56, 4418-4426.

25. Nijveldt, R.J.; van Nood, E.; van Hoorn, D.E.; Boelens, P.G.; van Norren, K.; van Leeuwen, P.A. Flavonoids: A review of probable mechanisms of action and potential applications. Am. J. Clin. Nutr. 2001, 74, 418-425.

26. Ioannou, I.; Hafsa, I.; Hamdi, S.; Charbonnel, C.; Ghoul, M. Review of the effects of food processing and formulation on flavonol and anthocyanins behavior. J. Food Eng. 2012, 111, 208-217.

27. MacDonald-Wicks, L.K.; Wood, L.G.; Garg, M.L. Methodology for the determination of biological antioxidant capacity in vitro: A review. J. Sci. Food Agric. 2006, 86, 2046-2056.

28. AOAC. Official Methods of Analysis of AOAC International, 15th ed.; Association of Official Analytical of Official Aanalytical Communities: Washington, DC, USA, 1990.

29. Miller, G.L. Use of dinitrosalycilic acid reagent for the determination of reducing sugar. Anal. Chem. 1959, 31, 426-428.

30. Arnous, A.; Makris, D.P.; Kefalas, P. Effect of principal polyphenol components in relation to antioxidant characteristics of aged red wines. J. Agric. Food Chem. 2001, 49, 5736-5742.

31. Shen, Y.; Jin, L.; Xiao, P.; Lu, Y.; Bao, J. Total phenolics, flavonoids, antioxidant capacity in rice grain and their relations to grain color, size, and weight. J. Cereal Sci. 2009, 49, 106-111.

32. Brand-Williams, W.; Cuvelier, M.E.; Berset, C. Use of a free-radical method to evaluate antioxidant activity. LWT-Food Sci. Technol. 1995, 28, 25-30. 
33. Re, R.; Pellegrini, N.; Proteggente, A.; Pannala, A.; Yang, M.; Rice-Evans, C. Antioxidant activity applying an improved ABTS radical cation decolorization assay. Free Radic. Biol. Med. 1999, 26, 1231-1237.

34. Benzie, I.F.; Strain, J.J. The ferric reducing ability of plasma (FRAP) as a measure of antioxidant power: The FRAP assay. Anal. Biochem. 1996, 239, 70-76.

35. Oyaizu, M. Studies on products of the browning reaction: Antioxidative activities of browning reaction products prepared from glucosamine. Jpn. J. Nutr. Diet. 1986, 44, 307-315.

Sample Availability: Samples of black garlic are available from the authors.

(C)2014 by the authors; licensee MDPI, Basel, Switzerland. This article is an open access article distributed under the terms and conditions of the Creative Commons Attribution license (http://creativecommons.org/licenses/by/4.0/). 